\title{
Analysis of HPV Prevalence in Pairs of Cervical and Urine Samples from the Same Woman
}

\author{
Dong Hyeok Kim ${ }^{1,2, *}$, Hyunwoo Jin ${ }^{1,2, * *}$ and Kyung Eun Lee $\mathrm{L}^{1,2, \uparrow, * * *}$ \\ ${ }^{I}$ Department of Clinical Laboratory Science, College of Health Sciences, \\ Catholic University of Pusan, Busan 46252, Korea \\ ${ }^{2}$ Clinical Trial Specialist Program for In Vitro Diagnostics, Brain Busan 21 Plus Program, \\ Graduate School, Catholic University of Pusan, Busan 46252, Korea
}

\begin{abstract}
The main cause of cervical cancer is a persistent infection with high-risk human papillomavirus (HR-HPV). Cervical cancer is reported as a preventable cancer in more than $80 \%$ of cases with early diagnosis and appropriate treatment. Papanicolaou test (Pap test) has been a global strategy to prevent cervical cancer, and recently, HPV test has been reported to be effective against cervical cancer and precancerous lesions. However, pelvic examinations give patients anxiety, discomfort, pain, distress, and psychological stress. HPV test via a urine sample caused less physical and psychological stress and more advantage than the Pap test. Therefore, it is necessary to study the usefulness of the HPV test for easyto-collect urine samples. A total of 220 samples were collected from a pair of cervical and urine samples from 110 women and only 108 pairs of samples out of 110 were used because 2 cases were not amplified by $\beta$-globin. Among 108 pairs of cervical and urine samples, the prevalence of HPV was 37.0\% (40/108) in cervical samples, 34.3\% (37/108) in urine samples and HR-HPV was $22.2 \%$ (24/108) in cervical samples, $18.5 \%$ (20/108) in urine samples. In this study, urine samples showed a lower positive rate of HPV than cervical samples. There were many variables that could affect the condition of the urine sample. However, the HR-HPV agreement rate of the cervix and urine samples was $94.44 \%$ and the Kappa value was 0.823 , which was "almost perfect". Through these results showed the significance of cervical cancer screening using a urine sample. Cervical screening is crucial, as cervical cancer can be prevented in more than $90 \%$ of cases. Urine samples collected by non-invasive methods may have the potential advantage of increasing acceptance of cervical cancer screening. Therefore, it is necessary to develop a new cervical cancer screening strategy using urine samples through further study based on the results of this study.
\end{abstract}

Key Words: Cervical cancer, Human papillomavirus, HPV DNA test, Urine

\section{INTRODUCTION}

The main cause of cervical cancer is a persistent infection with human papillomavirus (HPV), and about 200 geno- types of HPV have been reported (Vergara et al., 2019). Cervical cancer is reported as a preventable cancer in more than $80 \%$ of cases with appropriate diagnosis and treatment. The introduction of cervical cancer screening programs in many developed countries has greatly reduced the incidence

Received: February 18, 2021 / Revised: March 29, 2021 / Accepted: March 29, 2021

* Graduate student, ${ }^{* *}$ Professor.

${ }^{\dagger}$ Corresponding author: Kyung Eun Lee. Department of Clinical Laboratory Science, College of Health Science, Catholic University of Pusan, Busan 46252, Korea.

Tel: +82-51-510-0562, Fax:+82-51-510-0568, e-mail: kelee@cup.ac.kr

(C) The Korean Society for Biomedical Laboratory Sciences. All rights reserved.

(c) This is an Open Access article distributed under the terms of the Creative Commons Attribution Non-Commercial License (http://creativecommons.org/licenses/by-nc/3.0/) which permits unrestricted non-commercial use, distribution, and reproduction in any medium, provided the original work is properly cited. 
of cervical cancer, indicating the importance of early diagnosis and prevention (WHO et al., 2020). An estimated 528,000 new cases of cervical cancer are predicted annually worldwide, accounting for 15.7 per 100,000 women in developing countries and 9.9 per 100,000 women in developed countries (Lim et al., 2017). In Korea, about 3,500 new cases of cervical cancer are reported every year. The incidence of cervical cancer was 8.7 per 100,000 women in 2017 , a decrease of $4.9 \%$ annually from 1999 to 2017 (Hong et al., 2020).

Papanicolaou test (Pap test) was a global strategy to prevent cervical cancer. Since the introduction of the Pap test, the incidence and mortality of cervical cancer have decreased (Safaeian et al., 2007). HPV DNA screening was shown to be more effective than cytology screening in pre-malignant and malignant cervical lesions (van Rosmalen et al., 2012; Ronco et al., 2014). However, both Pap and HPV tests require a pelvic examination. These exams give patients anxiety, discomfort, pain, distress, and psychological stress (Virtanen et al., 2014; Sultana et al., 2015). Therefore, the development of non-invasive sample collection methods would have the potential advantage of increasing the acceptance of cervical cancer screening (Bernal et al., 2014). Using easy-to-collect urine would be appropriate for that purpose. the recent literature showed that an HPV test via a urine sample caused less physical and psychological stress and more advantage than the Pap test (Frati et al., 2015; Pattyn et al., 2019). Therefore, the HPV test using a urine sample is considered significant because the physical and psychological stress on the patient is low. However, the urine is not a sample from the site of HPV infection (Khunamornpong et al., 2016). Hence, using urine as a cervical screening sample requires data accumulation through comparison with cervical samples.

In the present study, paired cervical and urine samples were collected from women who visited gynecology and compared HPV prevalence with cervical samples through reverse blot hybridization assay (REBA) to evaluate the significance of urine samples.

\section{MATERIALS AND METHODS}

\section{Participants and clinical samples}

A total of 220 samples were collected from 110 women with a pair of cervical and urine samples who visited the obstetrics and gynecology department between January to June in 2020. This study was approved by the Institutional Ethics Committee of Catholic University of Pusan (Approval number CUPIRB-2020-01-011). A total of 110 women aged between 20 and 69 years, with an average age of 40.9 years, were recruited in the study.

\section{Genomic DNA extraction from cervical and urine sam- ples}

DNA extraction was performed using 5\% Chelex $^{\circledR} 100$ Resin solution (BIO-RAD, CA, USA) according to manufacturer's recommendations. $200 \mu \mathrm{L}$ of the sample was transferred to a DNase-free tube, centrifuged at $8,000 \times \mathrm{g}$ for 10 minutes, discarded the supernatant, and vortexed and spin down by adding $100 \mu \mathrm{L}$ of $5 \%$ Chelex $^{\circledR} 100$ Resin solution to the remaining cell pellet. Then, incubate at $100{ }^{\circ} \mathrm{C}$ for 10 minutes, centrifuge the sample at $11,000 \times \mathrm{g}$ for 10 minutes, and transfer the supernatant to a new E-tube. The extracted genomic DNA was checked for concentration and purity through NanoDrop 2000 (Thermo Fisher Scientific, Wilmington, DE, USA) and stored at a freezing temperature of $-18^{\circ} \mathrm{C}$ before analysis.

\section{HPV genotyping by reverse blot hybridization (REBA) assay}

HPV genotypes were determined using the REBA HPVID $^{\circledR}$ (YD Diagnostics, Yongin, Korea) on the automated HybREAD480 ${ }^{\circledR}$ (YD Diagnostics, Yongin, Korea), which could genotype 18 HR-HPV types $(16,18,26,31,33,35$, $39,45,51,52,53,56,58,59,66,68,69$, and 73), one medium-risk HPV type (34), and 13 low-risk HPV types (6, 11, 32, 40, 42, 43, 44, 54, 70, 72, 81, 84, and 87). This system targets the $\mathrm{L} 1$ gene, which encodes the capsid protein of HPV. This method required nested PCR to amplify target regions including MY11 \& MY09 and GP5 \& GP6 with two pairs of primers. The PCR product was mixed with 
denaturation solution, denatured at $25^{\circ} \mathrm{C}$ for 5 minutes, dispensed on REBA membrane strips, and diluted with $970 \mu \mathrm{L}$ hybridization solution. The denatured single-stranded PCR products were hybridized on a membrane strip at $50^{\circ} \mathrm{C}$ for $30 \mathrm{~min}$. The staining solution and a 1:50 dilution of NBT/BCIP (Roche Diagnostics, Mannheim, Germany) were added and incubated until a color change was detected, finally the band pattern was checked and interpreted.

\section{Statistical analysis}

Concordance between date of test was evaluated using the Kappa statistic (Cohen's Kappa, $\kappa$ ) and defined as "poor" (=0), "slight" $(0.01<\kappa<0.20)$, "fair" $(0.21<\kappa<0.40)$, "moderate" $(0.41<\kappa<0.60)$, "substantial" $(0.61<\kappa<0.80)$, "almost perfect" $(0.81<\kappa<1)$ or "perfect" $(=1)$.

\section{RESULTS}

\section{Prevalence of HPV in pairs of cervical and urine samples}

All 110 paired cervical and urine samples collected, only 108 pairs of samples were used in this study because 2 cases were not amplified by $\beta$-globin.

Depending on the sample type, the prevalence of HPVpositive determined was $37.0 \%$ (40/108) in cervical samples and $34.3 \%(37 / 108)$ in urine samples. Of the $25.0 \%(27 /$ $108)$ in which both the cervical and urine samples were positive, $23.1 \%(25 / 108)$ had the same HPV genotype. In both the cervical and urine samples, 53.7\% (58/108) were HPV-negative, $12.0 \%$ (13/108) cases were HPV-positive only in the cervical samples and 9.3\% (10/108) were HPV- positive only in the urine samples. The concordance rate of HPV detection between cervical and urine samples was $76.85 \%(\kappa=0.54 ; 95 \%$ IC: $0.44 \sim 0.63$, moderate) (Table 1$)$.

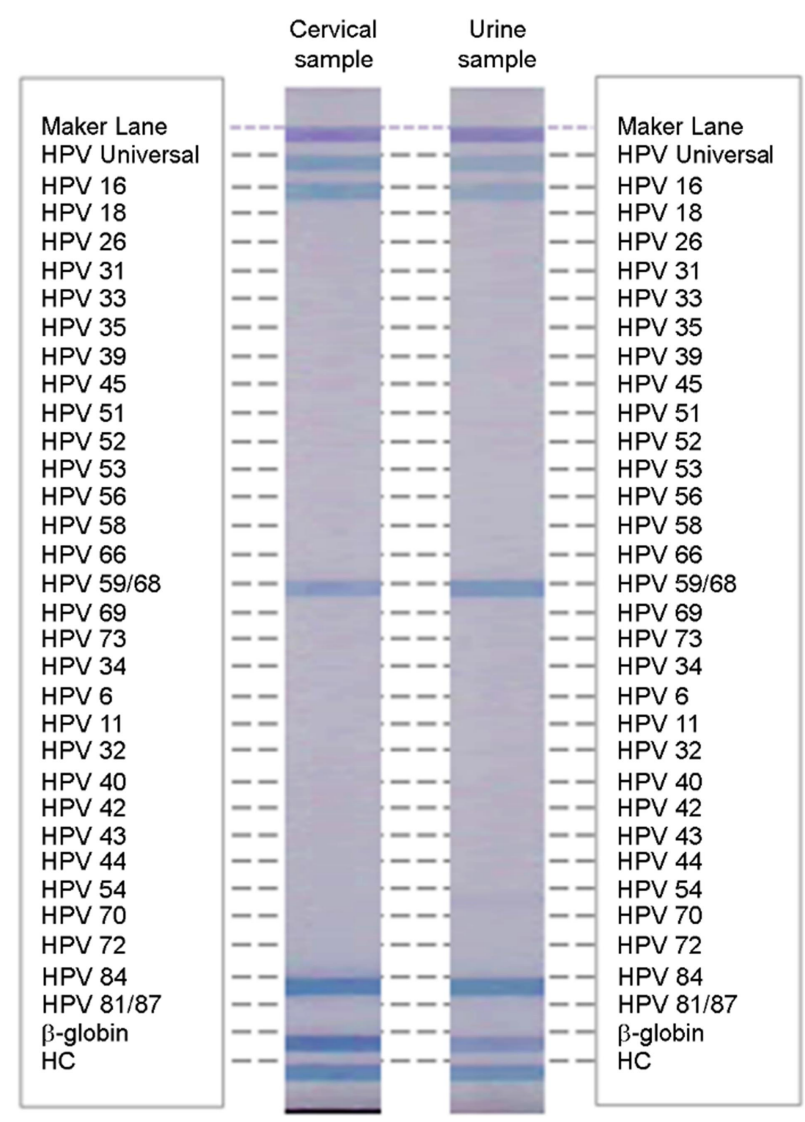

Fig. 1. Results of reverse blot hybridization assay in cervical and urine samples. High-risk HPV genotypes HPV 16, HPV 59/68 and low-risk HPV 84 were detected in cervical and urine sample from the same woman.

Table 1. Comparison of HPV detection rate and HPV genotype concordance rate between cervical and urine samples

\begin{tabular}{|c|c|c|c|c|c|c|}
\hline & & & \multicolumn{2}{|c|}{ Urine samples } & \multirow{2}{*}{$\begin{array}{l}\text { Concordance } \\
\text { rate }(\%)\end{array}$} & \multirow[b]{2}{*}{$\kappa(95 \% \mathrm{IC})$} \\
\hline & & & $\begin{array}{c}\text { Positive } \\
\text { n (\%) }\end{array}$ & $\begin{array}{c}\text { Negative } \\
\mathrm{n}(\%)\end{array}$ & & \\
\hline \multirow{4}{*}{$\begin{array}{l}\text { Cervical } \\
\text { samples }\end{array}$} & \multirow{2}{*}{ HPV } & Positive & $27(25.0)$ & $13(12.0)$ & \multirow{2}{*}{76.85} & \multirow{2}{*}{$\begin{array}{c}0.54 \\
(0.44 \sim 0.63)\end{array}$} \\
\hline & & Negative & $10(9.3)$ & $58(53.7)$ & & \\
\hline & \multirow{2}{*}{ HR-HPV } & Positive & $18(16.7)$ & $4(3.7)$ & \multirow{2}{*}{94.44} & \multirow{2}{*}{$\begin{array}{c}0.82 \\
(0.72 \sim 0.92)\end{array}$} \\
\hline & & Negative & $2(1.9)$ & $84(77.8)$ & & \\
\hline
\end{tabular}

Abbreviations: HR-HPV, high-risk HPV

HR-HPV is $16,18,26,31,33,35,39,45,51,52,53,56,58,59,66,68,69$ and 73

$\kappa:$ Cohen's kappa, 0.54; "moderate" $(0.41<\kappa<0.60), 0.82$; "almost perfect" $(0.81<\kappa<1)$ 


\section{Prevalence and distribution of HR-HPV in cervical and urine sample pairs}

HR-HPV was detected in $22.2 \%(24 / 108)$ of the cervical samples and $18.5 \%(20 / 108)$ cases of the urine samples. The

Table 2. High-risk HPV genotype distribution due to single or multiple infections in cervical and urine samples by REBA assay

\begin{tabular}{ccc}
\hline \hline $\begin{array}{c}\text { HR-HPV } \\
\text { genotype }\end{array}$ & $\begin{array}{c}\text { Cervical } \\
\mathrm{n}(\%)\end{array}$ & $\begin{array}{c}\text { Urine } \\
\mathrm{n}(\%)\end{array}$ \\
\hline 16 & $3(9.1)$ & $3(11.1)$ \\
18 & $2(6.1)$ & - \\
31 & $1(3.0)$ & $1(3.7)$ \\
33 & $1(3.0)$ & $3(11.1)$ \\
35 & $2(6.1)$ & $2(7.4)$ \\
39 & $1(3.0)$ & - \\
45 & $2(6.1)$ & $1(3.7)$ \\
51 & $1(3.0)$ & $1(3.7)$ \\
52 & $2(6.1)$ & $2(7.4)$ \\
53 & $4(12.1)$ & $3(11.1)$ \\
56 & $5(15.2)$ & $4(14.8)$ \\
58 & $1(3.0)$ & $2(7.4)$ \\
59 & $4(12.1)$ & $3(11.1)$ \\
68 & $4(12.1)$ & $3(11.1)$ \\
\hline Total & $33(100)$ & $28(100)$ \\
\hline
\end{tabular}

Abbreviations: REBA, reverse blot hybridization assay same HPV genotype was detected in all 16.6\% (18/108) of cervical and urine sample pairs. In both the cervical and urine samples, 77.8\% (84/108) were HPV-negative, 3.7\% (4/108) were HPV-positive only in the cervical samples and $1.9 \%(2 / 108)$ were HPV-positive only in the urine samples. The concordance rate of HPV detection between cervical and urine samples was $94.44 \%(\kappa=0.823 ; 95 \%$ IC: $0.72 \sim$ 0.92, almost perfect) (Table 1, Fig. 1).

The most frequently detected HR-HPV genotype in the cervical sample was HPV 56 (15.2\%, 5/33), HPV 16 (9.1\%, 3/33), and HPV 18 (6.1\%, 2/33). The most frequently detected HR-HPV genotype in the urine samples was HPV 56 (14.8\%, 4/28) and HPV 16 (11.1\%, 3/28), and HPV 18

Table 3. High-risk HPV prevalence by age group

\begin{tabular}{cccc}
\hline \hline \multirow{2}{*}{$\begin{array}{c}\text { Age interval } \\
\text { (years) }\end{array}$} & $\begin{array}{c}\text { Total cases } \\
\mathrm{n}(\%)\end{array}$ & \multicolumn{2}{c}{ HR-HPV positive } \\
\cline { 3 - 4 } & $23(21.3)$ & $8(33.3)$ & $6(30.0)$ \\
$\mathrm{n}(\%)$ & $\begin{array}{c}\text { Urine } \\
\mathrm{n}(\%)\end{array}$ \\
\hline 29 & $33(30.6)$ & $9(37.6)$ & $7(35.0)$ \\
$40 \sim 39$ & $22(20.4)$ & $1(4.2)$ & $3(15.0)$ \\
$50 \sim 59$ & $19(17.6)$ & $3(12.5)$ & $2(10.0)$ \\
$60 \sim$ & $11(10.2)$ & $3(12.5)$ & $2(10.0)$ \\
\hline Total & $108(100)$ & $24(100)$ & $20(100)$ \\
\hline
\end{tabular}

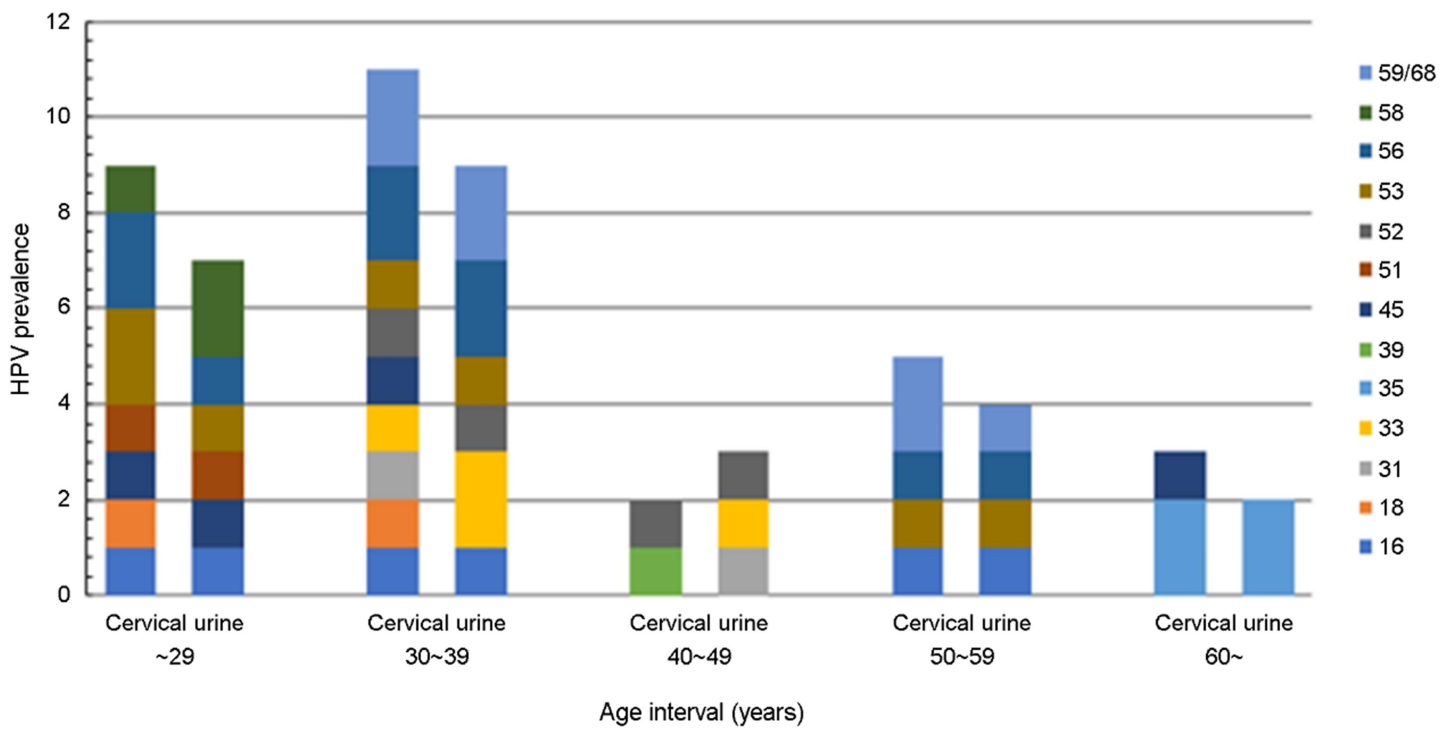

Fig. 2. Distribution of high-risk HPV genotypes by age in cervical and urine samples. Through the reverse blot hybridization assay, high-risk HPV was most detected in the 30's, followed by 20 's. 
was not detected. HPV 52 was detected $6.1 \%(2 / 33)$ in the cervical samples, and 7.4\% (2/28) urine samples. HPV 58 was detected in $3.0 \%(1 / 33)$ in cervical sample and $7.4 \%$ $(2 / 28)$ in the urine sample (Table 2$)$.

\section{HR-HPV prevalence and distribution by age in cervical and urine samples}

HR-HPV showed the highest detection rate in the cervical samples in the 20 's group $(34.8 \%, 8 / 23)$, followed by the 30 's group $(27.3 \%, 9 / 33)$. Likewise, in the urine sample, the 20 's group were the most $(26.1 \%, 6 / 23)$, and the 30 's group $(21.2 \%, 7 / 33)$ were the next (Table 3$)$.

The cervical samples had the highest positive rate of HRHPV in the 20's group, followed by the 30 's group. In the 20's group, HPV 53 and HPV 56 were the most common $(22.2 \%, 2 / 9)$ in the cervical samples, and in the urine samples, HPV 58 was the most common $(28.6 \%, 2 / 7)$. In the 30 's group, HPV 56 and HPV 59/68 were the most common $(18.1 \%, 2 / 11)$ in the cervical samples and HPV 33, HPV 56, and HPV 59/68 were the most common $(22.2 \%, 2 / 9)$ in the urine sample (Fig. 2).

\section{DISCUSSION}

Cervical screening is crucial, as cervical cancer can be prevented in more than $90 \%$ of cases with early diagnosis (Asciutto et al., 2018). Traditionally, cervical screening is performed using cytological tests, which has reduced the incidence and mortality of cervical cancer in many countries (WHO et al., 2020). However, the sensitivity of cervical screening is not sufficient to prevent cervical cancer (Cuzick et al., 2006; van den Akker-van Marle et al., 2002). The HPV test is reportedly more sensitive to the detection of advanced squamous lesions than cytology-based screening alone (van Rosmalen et al., 2012; Ronco et al., 2014; Aitken et al., 2019). The HPV test was also proposed as another method of Pap test (Huh et al., 2015). However, cervical sample collection has limitations due to the stress on the patient (Virtanen et al., 2014; Sultana et al., 2015). Therefore, in this study, the prevalence and distribution of HPV was compared and analyzed with the cervical sample to determine the significance of the urine samples.
Other study that a meta-analysis of the overall prevalence of HPV infection in the cervical showed $25.41 \%$ (105 studies; 95\% CI 22.71 28.32; I $2=98 \%$ ), and the prevalence of HR-HPV genotypes was 17.65\% (44 studies; 95\% CI 4.80 20.92; I 2 = 96\%) (Colpani et al., 2020). In this study, 37.0\% (40/108) of cervical samples were HPV positive, and 34.3\% (37/108) of urine samples were HPV positive. Only HRHPV was detected in $22.2 \%$ (24/108) of the cervical samples and $18.5 \%$ (20/108) cases of the urine samples were positive. Therefore, the HPV infection rate in this study was relatively higher than that of the meta-analysis result. Recently, studies on HPV detection in urine samples have been continuously reported. In another study comparing HPV detection in cervical and urine samples, the HPV detection rate was 39.6\% $(65 / 164)$ in cervical samples and $32.3 \%(53 / 164)$ in urine samples, which was similar to the results of this study (Nilyanimit, 2017). However, in another study, the prevalence of cervical samples was $64.4 \%$ (132/205), and the prevalence of urine samples was $37.9 \%$ (74/195), indicating a distinct difference between the detection rates of HPV between cervical and urine samples (Asciutto et al., 2018). Therefore, using urine as a cervical examination sample requires data accumulation through comparison with cervical samples.

Among the 108 study subjects, 20's and 30's groups showed high prevalence of HR-HPV. Among 23 cases $(21.3 \%, 23 / 108)$ in the 20's group, $34.8 \%(8 / 23)$ of cervical samples and $26.1 \%(6 / 23)$ of urine samples were HR-HPV positive. Of the 33 cases $(30.6 \%, 33 / 108)$ in the 30 's group, $27.3 \%(9 / 33)$ of cervical samples and $21.2 \%(7 / 33)$ of urine samples were HR-HPV positive. In Korea, the mortality and incidence rate of cervical cancer has declined over the past decade, while the HPV infection rate among younger age groups is increasing (Hong et al., 2020; Kim et al., 2018). Therefore, the results of this study show that younger age groups have a high potential risk of cervical cancer due to persistent HR-HPV infection, indicating the need to increase acceptance of cervical cancer screening.

In a recent study, the concordance of real-time PCR-based HPV test results (Roche Cobas HPV, Anyplex II HPV and RealTime HR-S HPV) of urine and cervical samples was 81.2 86.1\% (Cho et al., 2019). Likewise, in other literature 
comparative studies of HPV detection in cervical and urine samples have been continuously reported (Bernal et al., 2014). However, in most studies using real-time PCR, as in the above studies, HPV detection genotypes are HPV 16, HPV 18, and non-16/18 HR-HPV. Real-time PCR-based non-16/18 HR-HPV detection mostly identifies more than 10 genotypes at the same time. But this study distinguishes 42 HPV genotypes (18 HR-HPV types, one medium-risk HPV type, 13 low-risk HPV types) by REBA HPV-ID ${ }^{\circledR}$, so the concordance rate seems to be relatively low. Analyzing only the HR-HPV genotype in this study, the concordance rate was $94.44 \%$ and the Kappa value was 0.823 , indicating "almost perfect" this result showed a higher concordance rate than other studies. Interestingly, the genotypes in both cervical and urine of HR-HPV positive were agreement.

HPV 16 and HPV 18 are known to be responsible of $70 \%$ of cervical cancers and precancerous cervical lesions (WHO et al., 2020). In this study, HPV 16 detected in cervical samples was detected in $2.8 \%(3 / 108)$, and all of them were detected in urine samples. However, HPV 18 detected in the cervical was not detected in urine samples. The reason for these results may be that the urine sample does not contain enough isolated cervical cells to detect HPV (Vorsters et al., 2012). In addition, urine samples contain insufficient cervical cells and may vary depending on collection, storage, DNA extraction, and study population (Vorsters et al., 2014). Therefore, it is necessary to develop appropriate collection, storage, and DNA extraction methods to efficiently use urine samples as HPV test samples.

In this study, the HR-HPV concordance rate between the cervical and urine samples was $94.4 \%$ and HR-HPV genotypes were agreement in $16.7 \%(18 / 108)$ of both type samples. Through these results confirmed the significance of cervical cancer screening using a urine sample. However, urine samples showed a lower positive rate of HPV than cervical samples. This is because HPV-infected cells detected in a urine sample may be independent of cervical exfoliative cells (Khunamornpong et al., 2016).

Cervical screening is crucial, as cervical cancer can be prevented in more than $90 \%$ of cases with early diagnosis (Asciutto et al., 2018). According to the results of this study, it seems inappropriate to use it for cervical cancer screening alone through HPV test using a urine sample. However, urine samples collected by non-invasive methods may have the potential advantage of increasing acceptance of cervical examinations (Bernal et al., 2014). Therefore, it is necessary to develop a new cervical cancer screening strategy using urine samples through further study based on the results of this study.

\section{ACKNOWLEDGEMENT}

Following are results of a study on the "Leaders in Industry-university Cooperation +" Project, supported by the Ministry of Education and National Research Foundation of Korea.

\section{CONFLICT OF INTEREST}

No potential conflict of interest relevant to this article was reported.

\section{REFERENCES}

Aitken CA, van Agt HME, Siebers AG, van Kemenade FJ, Niesters HGM, Melchers WJG, Vedder JEM, Schuurman R, van den Brule AJC, van der Linden HC, Hinrichs JWJ, Molijn A, Hoogduin KJ, van Hemel BM, de Kok IMCM. Introduction of primary screening using high-risk HPV DNA detection in the Dutch cervical cancer screening programme: a populationbased cohort study. BMC Med. 2019. 17: 228.

Asciutto KC, Ernstson A, Forslund O, Borgfeldt C. Self-sampling with HPV mRNA analyses from vagina and urine compared with cervical samples. J Clin Virol. 2018. 101: 69-73.

Bernal S, Palomares JC, Artura A, Parra M, Cabezas JL, Robles A, Martín Mazuelos E. Comparison of urine and cervical samples for detecting human papillomavirus (HPV) with the Cobas 4800 HPV test. J Clin Virol. 2014. 61: 548-552.

Cho HW, Ouh YT, Hong JH, Min KJ, So KA, Kim TJ, Paik ES, Lee JW, Moon JH, Lee JK. Comparison of urine, self-collected vaginal swab, and cervical swab samples for detecting human papillomavirus (HPV) with Roche Cobas HPV, Anyplex II HPV, and RealTime HR-S HPV assay. J Virol Methods. 2019 269: $77-82$.

Colpani V, Soares Falcetta F, Bacelo Bidinotto A, Kops NL, Falavigna M, Serpa Hammes L, Schwartz Benzaken A, Kalume Maranhão AG, Domingues CMAS, Wendland EM. Prevalence of human papillomavirus (HPV) in Brazil: A 
systematic review and meta-analysis. PLoS One. 2020. 15: e0229154.

Cuzick J, Clavel C, Petry KU, Meijer CJ, Hoyer H, Ratnam S, Szarewski A, Birembaut P, Kulasingam S, Sasieni P, Iftner T. Overview of the European and North American studies on $\mathrm{HPV}$ testing in primary cervical cancer screening. Int J Cancer. 2006. 119: 1095-1101.

Frati ER, Martinelli M, Fasoli E, Colzani D, Bianchi S, Binda S, Olivani P, Tanzi E. HPV Testing from Dried Urine Spots as a Tool for Cervical Cancer Screening in Low-Income Countries. Biomed Res Int. 2015. 2015: 283036.

Hong S, Won YJ, Park YR, Jung KW, Kong HJ, Lee ES; Community of Population-Based Regional Cancer Registries. Cancer Statistics in Korea: Incidence, Mortality, Survival, and Prevalence in 2017. Cancer Res Treat. 2020. 52: 335-350.

Huh WK, Ault KA, Chelmow D, Davey DD, Goulart RA, Garcia FA, Kinney WK, Massad LS, Mayeaux EJ, Saslow D, Schiffman M, Wentzensen N, Lawson HW, Einstein MH. Use of primary high-risk human papillomavirus testing for cervical cancer screening: interim clinical guidance. Gynecol Oncol. 2015. 136: 178-182.

Khunamornpong S, Settakorn J, Sukpan K, Lekawanvijit S, Katruang N, Siriaunkgul S. Comparison of Human Papillomavirus Detection in Urine and Cervical Samples Using HighRisk HPV DNA Testing in Northern Thailand. Obstet Gynecol Int. 2016. 2016: 6801491.

Kim MA, Han GH, Kim JH, Seo K. Current Status of Human Papillomavirus Infection and Introduction of Vaccination to the National Immunization Program in Korea: an Overview. J Korean Med Sci. 2018. 33: e331.

Lim MC, Lee DH, Hwang SH, Hwang NR, Lee B, Shin HY, Jun JK, Yoo CW, Lee DO, Seo SS, Park SY, Joo J. Comparison of the Abbott RealTime High Risk HPV test and the Roche cobas 4800 HPV test using urine samples. J Virol Methods. 2017. 243: 74-79.

Nilyanimit P, Chansaenroj J, Karalak A, Laowahutanont P, Junyangdikul P, Poovorawan Y. Comparison of human papillomavirus (HPV) detection in urine and cervical swab samples using the HPV GenoArray Diagnostic assay. PeerJ. 2017. 5: e3910.

Pattyn J, Van Keer S, Biesmans S, Ieven M, Vanderborght C, Beyers K, Vankerckhoven V, Bruyndonckx R, Van Damme P, Vorsters A. Human papillomavirus detection in urine: Effect of a first-void urine collection device and timing of collection. J Virol Methods. 2019. 264: 23-30.
Ronco G, Dillner J, Elfström KM, Tunesi S, Snijders PJ, Arbyn M, Kitchener H, Segnan N, Gilham C, Giorgi-Rossi P, Berkhof J, Peto J, Meijer CJ; International HPV screening working group. Efficacy of HPV-based screening for prevention of invasive cervical cancer: follow-up of four European randomised controlled trials. Lancet. 2014. 383: 524-532.

Safaeian M, Solomon D, Castle PE. Cervical cancer prevention-cervical screening: science in evolution. Obstet Gynecol Clin North Am. 2007. 34: 739-760.

Sultana F, Mullins R, English DR, Simpson JA, Drennan KT, Heley S, Wrede CD, Brotherton JM, Saville M, Gertig DM. Women's experience with home-based self-sampling for human papillomavirus testing. BMC Cancer. 2015. 15: 849.

van den Akker-van Marle $\mathrm{ME}$, van Ballegooijen $\mathrm{M}$, van Oortmarssen GJ, Boer R, Habbema JD. Cost-effectiveness of cervical cancer screening: comparison of screening policies. J Natl Cancer Inst. 2002. 94: 193-204

van Rosmalen J, de Kok IM, van Ballegooijen M. Cost-effectiveness of cervical cancer screening: cytology versus human papillomavirus DNA testing. BJOG. 2012. 119: 699-709.

Vergara N, Balanda M, Vidal D, Roldán F, S Martín H, Ramírez E. Detection and quantitation of human papillomavirus DNA in peripheral blood mononuclear cells from blood donors. J Med Virol. 2019. 91: 2009-2015.

Virtanen A, Nieminen P, Niironen M, Luostarinen T, Anttila A. Self-sampling experiences among non-attendees to cervical screening. Gynecol Oncol. 2014. 135: 487-494.

Vorsters A, Micalessi I, Bilcke J, Ieven M, Bogers J, Van Damme P. Detection of human papillomavirus DNA in urine. A review of the literature. Eur J Clin Microbiol Infect Dis. 2012. 31: 627-640.

Vorsters A, Van den Bergh J, Micalessi I, Biesmans S, Bogers J, Hens A, De Coster I, Ieven M, Van Damme P. Optimization of HPV DNA detection in urine by improving collection, storage, and extraction. Eur J Clin Microbiol Infect Dis. 2014. 33: 2005-2014.

World Health Organization 2020. Human Papillomavirus (HPV) and Cervical Cancer 2020

https://doi.org/10.15616/BSL.2021.27.1.28

Cite this article as: $\mathrm{Kim} \mathrm{DH}$, Jin H, Lee KE. Analysis of HPV Prevalence in Pairs of Cervical and Urine Samples from the Same Woman. Biomedical Science Letters. 2021. 27: 28-34. 